\title{
Prevalence of Organizational Stress, Burnout and Work-Related Musculoskeletal Discomfort (WMSD) among Civil Engineers - An Observational Study
}

\author{
Himali S. Gajjar', T. Kanna Amarnath ${ }^{2}$ \\ ${ }^{1}$ Postgraduate Physiotherapy Student, Ahmedabad Institute of Medical Sciences (AIMS) affiliated to Gujarat \\ University, Ahmedabad, Gujarat, India. \\ ${ }^{2}$ Principal and Senior Lecturer, Ahmedabad Institute of Medical Sciences (AIMS) affiliated to Gujarat \\ University, Ahmedabad, Gujarat, India. \\ Corresponding Author: Himali S. Gajjar
}

\begin{abstract}
Introduction: Organizational stress is an emotional, behavioral, physiological response to aggressive $\&$ harmful aspect of work, work environment and organization climate. Burnout is state of mental exhaustion caused by excessive \& prolonged stress. High work demand, poor work control and weak social support may create circumstances for development of stress among Civil engineers.

Purpose: The construction industry as a whole has been suffering from mental stress due to range of stressors imposed on the work force, resulting in behavioral habits which are not conductive to a healthy lifestyle; physical symptoms signalling burnout, chronic stress and depression which should be managed on time. Here arises the need to find Prevalence of organizational stressor, burnout and Work-related MSD among Civil Engineers.

Methodology: 110 Participants of both genders were asked to fill Standardized scales "organizational stressor scale", "burnout questionnaire" \& "Cornell Musculoskeletal Discomfort Questionnaires (CMDQ)" by personal interview from construction sites of Ahmedabad. Datasheet compiled in Microsoft Excel.

Result: Organizational stressor shows:- $18.18 \%$ mild stress, $76.36 \%$ moderate stress \& $5.45 \%$ severe stress. On burnout scale $60.9 \%$ has fair chance of burning out, $5 \%$ has begun to burnout \& $3 \%$ has advanced stage of burnout. CMDQ shows maximum affection of pain in knee \& neck.

Conclusion: Civil engineers have moderate level of organizational stress and have moderate to high amount of job related stress which have begun to burnout, they are susceptible for Work related MSD with significant prevalence for knee pain.
\end{abstract}

Keywords: Burnout, Civil engineers, organizational stressor, work-related musculoskeletal disorder

\section{INTRODUCTION}

Organizational stress is an emotional \& behavioral response to aggressive \& harmful aspect of work, work environment \& organizational climate. Stressors are events, conditions or an external stimulus in surrounding that may trigger stress. The three main components of stress are stress itself, stressors, and strain. Although many tend to believe that stress is the direct result of organizational stressors, in actual fact, the 'person-environment' relationship is what depicts the existence and severity of stress. Stressors imposed on an individual creates a 'source of stress', which is dependent on the organizational environment, job aspects, and the individual's own resistance to stress. ${ }^{[1]}$

Burnout is a state of emotional, physical and mental exhaustion caused by prolonged \& excessive stress. In 2019, the World Health Organisation (WHO) recognised burnout as an 'occupational 
Himali S. Gajjar et.al. Prevalence of organizational stress, burnout and work-related musculoskeletal discomfort (WMSD) among civil engineers - an observational study.

phenomenon' in the 11 th revision of the International Classification of Disease (ICD) ${ }^{[2]}$ The syndrome is characterised by abnormal feelings of emotional exhaustion (EE), depersonalisation (DP), and a sense of reduced personal accomplishment (PA). The latter two dimensions are also known as 'cynicism' and 'professional efficacy' respectively. ${ }^{[3]}$ Symptoms exist on a scale of varying severity and affected individuals can go unrecognized due to the lack of awareness. ${ }^{[4]}$

Work related Musculoskeletal discomfort (WMSD) are injuries that affect the human body's movement or musculoskeletal system. Work related musculoskeletal discomfort (WMSD) constitute significant ergonomic problems encountered in the workplaces and ranking among the leading causes of occupational disability. ${ }^{[5]}$ Moreover the economic losses sequel to this, affects individuals, organizations and societies as a whole. ${ }^{[6]}$ Several studies have repeatedly implicated WMSD as a major cause of work-related disabilities and lost-time illness injuries in both developed and industrially developing countries. ${ }^{[7]}$

Civil engineer's plan, design and manage large construction projects. High physical work demand, long working hours and unfavorable work environment makes them susceptible for various physical and mental health related issues. Construction workers are constantly exposed to multiple ergonomic risk factors. ${ }^{[8]}$

The most comprehensive study regarding depression and injury was conducted among Chinese construction site personnel, which indicated that they were more than twice as likely to be injured in comparison to the general population. Up to $16 \%$ of the sample were significantly depressed and had some form of mental disorder (Jacobsen et al., 2013). Depression is one of the main outcomes of stress. ${ }^{[9]}$ The cognitive state of depression not only puts yourself, but fellow employees at risk of injury due to absent mindedness, not thinking 'clearly', or in a worst case, suicidal ideations (Goldenhar et al., 2003). ${ }^{[10]}$

\section{NEED OF THE STUDY}

Stress is inevitable in today's complex life since right from the time of birth till death an individual is invariably exposed to various stressful situations. The threat of political and economic imbalances and uncertainties, unemployment, poverty, urbanisation and increased socio-economic complexities and innumerable other factors contribute to Stress in any profession (Aziz, 2004)

In this era, Challenges for a business is to satisfy their employees in order to cope up with the ever changing and evolving environment and to achieve success and remain in competition. In order to increase efficiency, effectiveness, productivity and job commitment of employees, the business must satisfy the needs of its employees by providing good working condition .For this candidate should be mentally \& physically fit.

Job satisfaction can be an indicator for someone's general mental well-being. If a person is unhappy at work, it does not seem likely that this person will be happy in general. Secondly, job satisfaction will improve happiness at work and consequently, will improve work motivation and job performance. Achieving a high level of employee performance is considered the common goal for many organizations. Employee's satisfaction could enhance to the success of an organization since employees who exhibit a higher level of satisfaction tend to put more effort in their jobs that may then lead to better job performance. This can impaired by several stressors present at working site. ${ }^{[11]}$

Certain responses indicate the presence of organizational stress in Civil engineers. It may manifest by the presence of headache, sleep disturbances, difficulty in concentration, short temper, upset stomach, job dissatisfaction, low morale and increased use of drug/alcohol/caffeine. 
Himali S. Gajjar et.al. Prevalence of organizational stress, burnout and work-related musculoskeletal discomfort (WMSD) among civil engineers - an observational study.

There are a number of workplace factors, called job stressors that make jobs stressful and difficult for Civil engineers to work effectively. Interpersonal relationships at work, such as conflicts with the behavior of supervisors, conflicts with colleagues, conflicts with subordinates and conflicts with management policies can cause dislike towards the job which results in mental and physical damage in form of stress, pain , fatigue, laziness or suicidal thoughts.

When satisfied at work, the civil engineers are likely to be more stable, productive and accomplished towards organization goals. According to research, human service workers who derive satisfaction from their work are more committed and provide better services, than those who are dissatisfied (Acker 1999). Job satisfaction involves employees' affective or emotional feelings, it has major consequences on their lives. ${ }^{[11]}$

Nowadays various measures are taken for Health and safety at working place but no measures taken for stress management. Currently limited studies have been conducted to identify stress and its causes in Civil engineering sector of construction industry. Furthermore cultural belief still remains that feeling stressed is seen as a weakness and that a person should be able to sort it out on their own. But there is dire need of a stress management intervention.

To understand stress, a person needs to understand the source of stress and various interrelated environmental conditions that enhance stressful situation. So here arises the need to find prevalence of organizational stress, burnout \& WMSD among civil engineers.

Aim of the study is to find prevalence of organizational stress, Burnout and work related musculoskeletal disorder among civil engineers.

Objectives of the study are as following:

To find out Prevalence of Organizational stress on Organizational Stressor Scale among Civil engineers.
To find out Prevalence of Burnout on Burnout Questionnaire among Civil Engineers.

To find out Prevalence of Work-Related Musculoskeletal Disorder on Cornell Musculoskeletal Discomfort Questionnaire among Civil Engineers

\section{MATERIAL AND METHODOLOGY}

A study was performed among 110

Civil Engineers. Samples were taken by convenient sampling method. Type of study: An observation Study

\section{Inclusion criteria:}

Both male \& female engineers

Age group - 24-34 years

Qualification: Diploma, Degree or Post graduation in civil engineering

Work experience $\geq 2$ years

Working hours $=6$ to 8 hours per day

\section{Exclusion criteria:}

Subject with Any medically diagnosed musculoskeletal, neurological, cardiovascular, psychological condition

Indoor office

\section{Outcome measures:}

Organizational stressor scale

Cornell Musculoskeletal Discomfort Questionnaire (CMDQ)

Burnout Questionnaire.

\section{PROCEDURE:}

Approval was obtained from the ethical committee prior to commencement of the study. The study was explained to all participants and informed consent was taken from all subjects. Participants were asked to fill Standardized scales "organizational stressor scale", "burnout questionnaire" \& "Cornell Musculoskeletal Discomfort Questionnaires (CMDQ)" by personal interview from various construction sites of Ahmedabad.

Organizational stressor scale: it is a Likert scale. It includes 33 item self-report tool each scored on a 5 point scale. A score of 1 indicates not at all work related stress, whereas a score of 5 indicates very much work related stress. ${ }^{[1]}$ 
Himali S. Gajjar et.al. Prevalence of organizational stress, burnout and work-related musculoskeletal discomfort (WMSD) among civil engineers - an observational study.

Burnout Questionnaire: it includes 28 questions, which suggests level of burnout among workers. ${ }^{[12]}$ the reliability and validity of burnout questionnaire is acceptable and can be used for assessing burnout in occupational population. (alpha = 0.82 to 0.85$)^{[13]}$

Cornell musculoskeletal discomfort questionnaire (CMDQ): is a 54-items questionnaire containing a body map diagram and questions about the prevalence of musculoskeletal ache, pain or discomfort in 18 regions of the body during the previous week. $(\text { alpha }=0.94)^{[14]}$

All outcome measures have high Test-Retest Reliability.

\section{STATISTICAL ANALYSIS}

Datasheet was compiled in Microsoft Excel 2010 and analysed using SPSS version 20.0 software for windows.

\section{RESULT}

Baseline characteristics of civil engineers are shown in Table 1.

Graph 1. Organizational stressor shows:- $18.18 \%$ subjects were suffer from mild organizational stress, $76.36 \%$ suffers from moderate stress, whereas $5.45 \%$ suffers from severe organizational stress. The mean score of organizational stress was $79.30 \pm 15.97$.

Table 1: Baseline characteristics of civil engineers

\begin{tabular}{|l|l|l|}
\hline $\begin{array}{l}\text { GENDER } \\
\text { (M:F) }\end{array}$ & $\begin{array}{l}\text { AGE GROUP } \\
\text { (MEAN } \pm \text { SD) }\end{array}$ & QUALIFICATION \\
\hline $110: 000$ & $29.092 \pm 2.48$ & $\begin{array}{l}\text { DIPLOMA(N=22) }: 20.9 \% \\
\end{array}$ \\
& & $\begin{array}{l}\text { B.E CIVIL(N=75) }: 68.18 \% \\
\text { M.E CIVIL (N=13): } 11.8 \%\end{array}$ \\
\hline
\end{tabular}

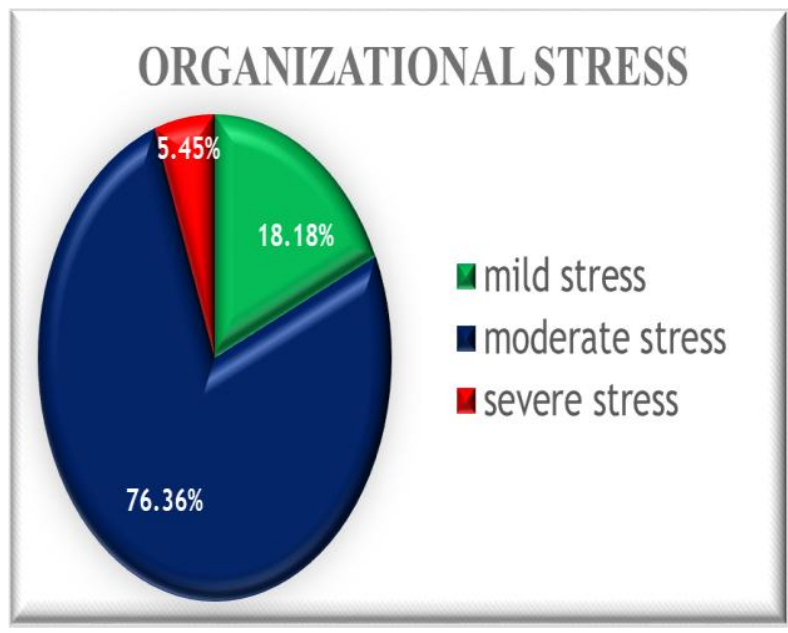

Graph 1: Pie chart for Organizational stress

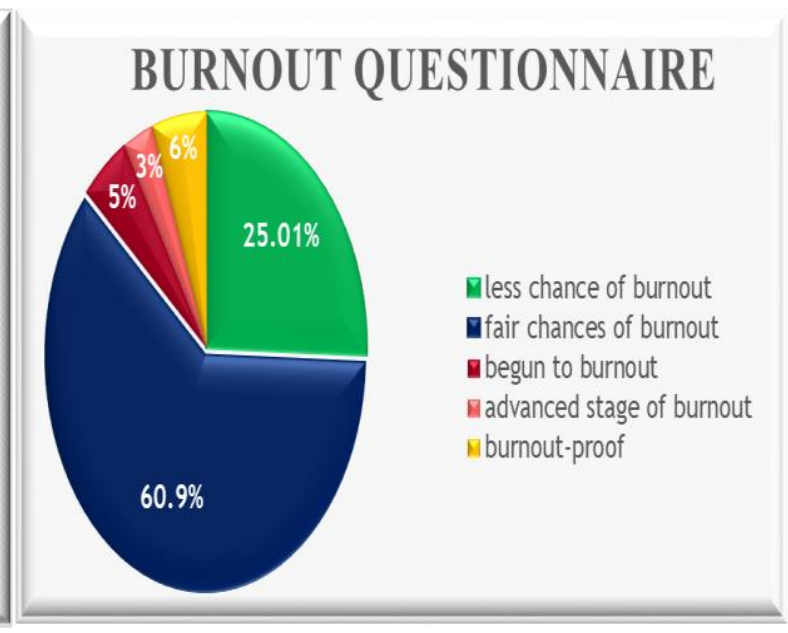

Graph 2: Pie chart for Burnout Questionnaire

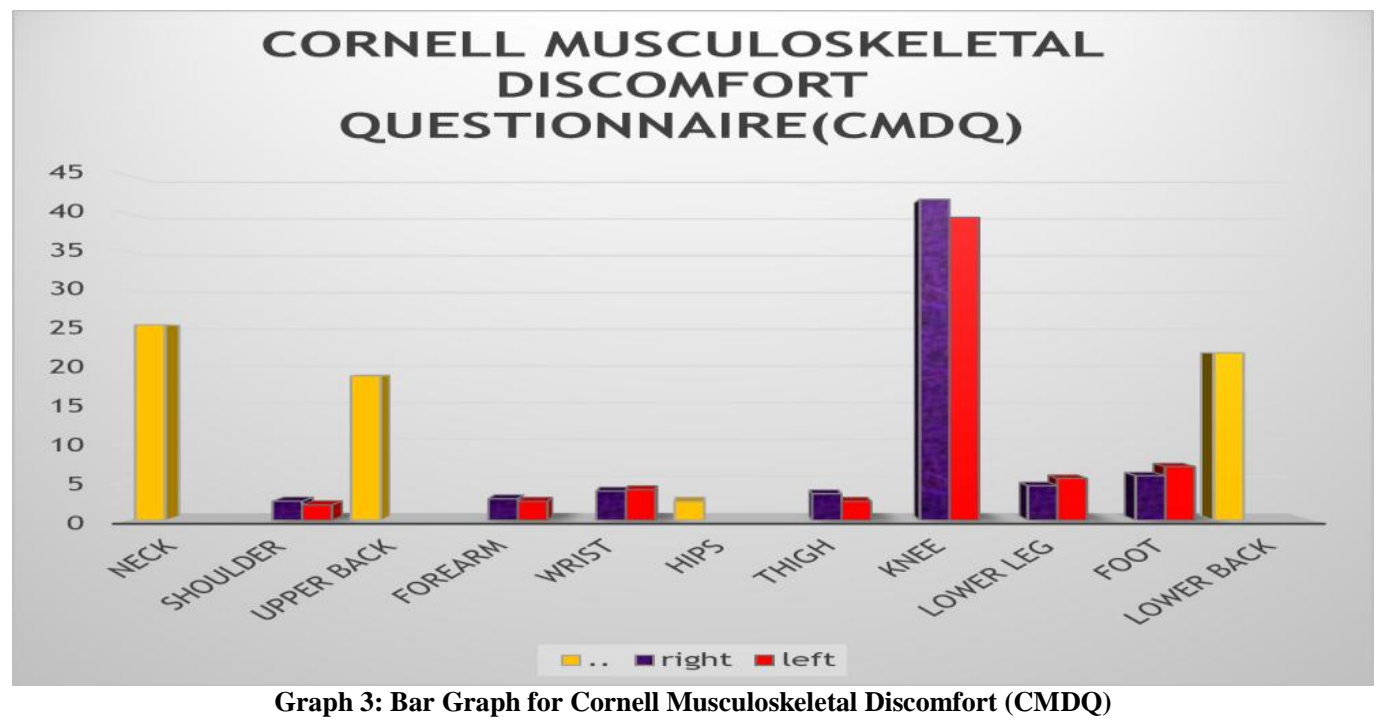


Himali S. Gajjar et.al. Prevalence of organizational stress, burnout and work-related musculoskeletal discomfort (WMSD) among civil engineers - an observational study.

Graph 2. Burnout questionnaire shows: $60.9 \%$ subjects have fair chance of burning out, $5 \%$ subjects may begun to burnout \& $3 \%$ has reached in advanced stage of burnout. The mean score of burnout scale was $64.727 \pm 12.647$.

Graph 3. Cornell Musculoskeletal Discomfort Questionnaires (CMDQ) shows maximum affection in knee, neck \& lower back respectively.

\section{DISCUSSION}

The aim of the study was to find Prevalence of Organizational stress, Burnout \& Work related MSD among Civil engineers.

The experience of stress reactions in the workplace is not an isolated phenomenon. A number of aspects of working life have been linked to stress and the different aspects of the work itself can be stressful, namely work overload, rolebased factors such as lack of power, and role conflict. The quality of the social environment in the workplace is also associated with stress. ${ }^{[11]}$

In this Study, Organizational stress was measured by Organizational stressor scale, results shows that most common stressors experienced at work place are poor salary, limited time to spend with family and friends, long working hours \& inadequate reward system. In addition to this inadequate time off, poor career growth potential, tight deadlines $\&$ inability express own opinions are other organizational stressors.

Sparks and Cooper, suggests that The conflict between home and work and the work impact on personal relationships is stressful. ${ }^{[1]}$ Also, physical conditions such as high noise levels, overcrowding in the workplace or a lack of privacy have been associated with stress.

Furthermore, occupational stress creates to be endemic to the current workplace and there are a number of workplace factors, called Stressors that make jobs stressful and difficult for number of employees in all sorts of industries.
Additional stressors related to interpersonal relationships at work are conflicts with supervisors, conflicts with colleagues, conflicts with subordinates and conflicts with management policies (Paul Spector, 2002). ${ }^{[15]}$ Kahn and Byosiere, (1992), Taylor, (1999) and Paul (2002) further pointed out that there are some other stressors in the organizational context, such as having insufficient resources to do the job (e.g., defective equipment or inadequate supplies), or low salaries structure. ${ }^{[15]}$ Research has clearly demonstrated that all of these stressors are connected with employees' health and wellbeing. As is characteristically found in various studies, higher levels of stressors (e.g., heavy workload and uncertainty about supervisors' expectations) were associated with physical symptoms, such as headaches, and poor job attitudes.

Burnout occurs when one feels overwhelmed, emotionally drained and unable to meet constant demands. Primary damage of burnout is physical damage. The negative effect of burnout spill over into every area of life- including home, social life and work. It can also cause long term change that makes one vulnerable to various illness. Burnout may be the result of unrelenting stress, but it isn't the same as too much stress. Being burned out means feeling empty and mentally exhausted, devoid of motivation and beyond caring. People experiencing burnout often don't see any positive change in their situations. ${ }^{[16]}$

Further findings of this study revealed that chronic work place stress that has not been successfully managed results in burnout. Present study shows that it is characterized by feeling of energy depletion, increased mental distance from a job \& feeling of negativism related to job. Few people can manage stress by themselves, but remaining subjects with moderate to severe organizational stress have begun to burnout and few of them has reached to severe level of burnout which should be managed on time. Burnout also produces symptoms like headache, insomnia, hypertension, 
Himali S. Gajjar et.al. Prevalence of organizational stress, burnout and work-related musculoskeletal discomfort (WMSD) among civil engineers - an observational study.

irritability, lower productivity, inability to focus, anxiety, fatigue, heart palpitation, forgetfulness, anger. It also increases alcohol/drug consumption and increases caffeine consumption. ${ }^{[17]}$

Final stage of burnout is habitual burnout, this means that the symptoms of burnout are so embedded in one's life that it's likely to experience a significant mental, physical or emotional problem, as opposed to occasionally experiencing stress or burnout. Common symptoms of this are depression, chronic sadness, suicidal thoughts, chronic mental and physical fatigue. Early stress management interventions and modification of working environment can prevent burnout. ${ }^{[18]}$

Study conducted by Hao Luo shows link between organizational stress and job burnout which states that maintaining an appropriate quantity \& quality of work could be important measure to prevent burnout. $^{[19]}$

Oyewobi et al. (2011) further established in their research that typical forms of behavioural symptoms / strains are headaches, anger, trouble sleeping, tension, back pain, sadness, stomach aches, and substance abuse. ${ }^{[20]}$

Stress related disorders includes a broad array of conditions like psychological disorder, emotional strain, maladaptive behaviors which eventually compromise a person's physical health and signalling burnout. The construction professionals have to do multitask on multiple projects, they might suffer from strain due to a number of factors such as excessive work load, long hours of work, role conflict, noise , risk and dangers at workplace that make them vulnerable for physical and mental stress. Bowen et al,2012. ${ }^{[21]}$

Poor ergonomics also contribute to injury and musculoskeletal discomfort. Subsequently higher occurrence of pain in knee, neck \& low back, as opposes to pain in other part of body has been found in the result of study. Pain is the result of such job related problems such as prolong standing posture, frequent twisting \& bending, inadequate time off \& long working hours. The main cause of pain in knee could be standing for long hours without sufficient breaks, poor base of support due to uneven ground, poor posture, frequent walking \& stair climbing on sites. Weak core muscle strength also contributes to pain in back, neck and knee.

Schneider argues that construction site personnel are at significant risk of musculoskeletal injury due to the type of work they perform. Construction site personnel's injuries are mostly in the form of MSDs, more specifically, sprains and strains. ${ }^{[22]}$

Stress \& Strain can impair the Civil Engineer's performance at work, diminish their alertness, and affect their problemsolving and decision-making abilities it causes anxiety /panic and may final build up to Burnout and Depression. ${ }^{[23]}$

Thus the finding of present study suggests that apart from nature of the work, Prolong organizational stressors can cause burnout and subsequent effect of both can contributes for musculoskeletal discomforts.

A literature review conducted on 658 construction site personnel in the USA revealed that the construction industry was ranked second after transportation in terms of sprain and strain injuries. A study conducted among 172 construction workers in the United States of America revealed that $75 \%$ had some form of musculoskeletal disorder (MSD), and that $16 \%$ consequently suffered from mental distress and burnout (Jacobsen et al., 2013). The American study, along with a study conducted among Chinese construction site personnel showed that the work force is twice as stressed as the general population, and found their risk of injury increased almost twofold due to being mentally stressed (Zheng et al., 2010). ${ }^{[24]}$

A problem of WMSD is extremely serious in the developing countries owing to poor working conditions Work environment, performance of work and ergonomics contribute to this condition and 
Himali S. Gajjar et.al. Prevalence of organizational stress, burnout and work-related musculoskeletal discomfort (WMSD) among civil engineers - an observational study.

the absence of effective work injury prevention programs. ${ }^{[25]}$

Hence this study concludes that Civil engineers are suffering from mild to moderate organizational stress, few of them may begun to burnout. Nature and Demand of work makes them susceptible for musculoskeletal discomfort. This should be managed on time to prevent further damage.

\section{Clinical Implication:}

Private organization need to address the Problem of work family imbalance, by providing more time off to spend with family. Organizations need to promote team building activities \& exercise among worker. Academic institute need to incorporate stress management into syllabus. ${ }^{[26]}$

Physiotherapists can help in Stress management by developing coping strategies, Relaxation exercise, Yoga \& Meditation. Psychological counselling \& Cognitive behavioural therapy is also helpful. Ergonomic advices, Postural correction, strengthening of weak muscles, core stability exercises can prevent musculoskeletal discomfort. Further proper guidance to reduce use of drugs/alcohol \& caffeine. Home treatment advised.

Future Study should include Research pertaining to the prevalence of stress management \& employee wellness interventions and Research pertaining to the implementation of a stress management model in a construction industry firm \& subsequent findings and improvements. Limitations of the study: female civil engineers were not included.

\section{CONCLUSION}

It is concluded that Civil Engineers have moderate level of organizational stress and have Moderate to high amount of job related stress which have begun to Burnout. Further the Prevalence of Pain in knee, neck $\&$ low back have been reported to be higher in comparison with pain in other part of the body.

\section{ACKNOWLEDGEMENTS}

Authors would like to thank the civil engineers who participated in the study.

\section{Conflict of Interest: None}

\section{Source of Funding: None}

\section{Ethical Approval: Approved}

\section{REFERENCES}

1. Erich HAYDAM. (2016). Mental stress among Civil engineering construction site agents and foremen in the nelson mandela bay metropole.,JCPMI Vol.6 (1):13751390,2016

2. World Health Organisation (WHO). Burnout an 'occupational phenomenon': International Classification of Diseases. WHO.

3. Barnes EL, Ketwaroo GA, Shields HM. Scope of Burnout Among Young Gastroenterologists and Practical Solutions from Gastroenterology and Other Disciplines. Dig Dis Sci. 2019 Feb 1; 64(2):302-6

4. Shanafelt TD, Bradley KA, Wipf JE, Back AL. Burnout and self-reported patient care in an internal medicine residency program. Ann Intern Med. 2002 Mar 5; 136(5):35867.

5. Alireza C, Nathan C, Baylor, Samson A. Prevalence and Risk of Musculoskeletal disorder in manual workers. Occupational Health 2007;34:456-60

6. Maul A, Laublic T, Khipstein A, KruegerH. Cause of low back pain among Nurses: Longitudinal study across eight years. Occu Environ Med 2003;60:497-500.

7. Alireza C, Sayed H, Marzieh T, Fatemeh G. Musculoskeletal problem in the communication industry. Ind $\mathrm{J}$ Occu Environ Med 2007;11

8. Waleed umer, The Prevalence of Musculoskeletal Disorders in the Construction Industry: A Systematic Review. JCSPHPC 15th Anniversary International Conference on "Innovations in Public Health Sciences"At: Faculty of Medicince, The Chinese University of Hong Kong 2016

9. Jacobsen, H.B., Caban-Martinez, A., Onyebeke, L.C., Sorensen, G., Dennerlein, J.T. and Reme, S.E. (2013). Construction 
Himali S. Gajjar et.al. Prevalence of organizational stress, burnout and work-related musculoskeletal discomfort (WMSD) among civil engineers - an observational study.

workers struggle with a high prevalence of mental distress, and this is associated with their pain and injuries. Journal of Occupational and Environmental Medicine, 55(10): 1197-1204

10. Goldenhar, L.M., Williams, L.J. and Swanson, N.G. (2003). Modelling relationships between job stressors and injury and near-miss outcomes for construction labourers. An International Journal of Work, Health \& Organisations, 17(3): 218-240

11. Dr. J. Rengamani, Impact of Occupational Stress on the Job Satisfaction of Civil Engineers in the Construction Companies in Chennai. International Journal of Civil Engineering and Technology, 9(8), 2018, pp. 542-550.

12. Michelle post, MA, LMFT from publish welfare, American Public Welfare Association, 1981, Vol. 39, No 1.

13. Dai JM, Yu HZ, Wang ZB, Fu H. reliability and validity of burnout Questionnaire in occupational population. Zhonghula Lao Dong Wei Sheng Zhi Ye Bin Za Zhi. 2006 Apr;24(4):229-31

14. Bilberg, R., Nørgaard, B., Roessler, K.K. et al. Test-retest reliability of Common Mental Disorders Questionnaire (CMDQ) in patients with total hip replacement (THR). BMC Psychol 2, 32 (2014).

15. Spector, P. Job satisfaction: Application, assessment, causes and consequences, Thousand Oaks, CA, Sage Publications, 1997 Vol. 3.

16. Melinda Smith, M.A., Jeanne Segal, Ph.D., and Lawrence Robinson, Burnout Prevention and Treatment. 2020 [internet] [cited 2020]

17. Maslach C, Leiter MP. Understanding the burnout experience: recent research and its implications for psychiatry. World Psychiatry. 2016 Jun;15(2):103-11.

18. CALMER ,Stages of burnout, chapter 9, Winona State University

19. Hao Luo, Relationship between occupational stress and job burnout among rural to urban migrant worker in Dongguan,
China: a cross sectional study. BMJ volume 6 ,issue 8.

20. Oyewobi, L.O., Adamu, A.D., Ganiyu, B.O. and Odelade, O.M. (2011)). Impact of stress management on the productivity of workers on Nigerian construction sites. Built Environment Journal, 8(2): 1-8.

21. Bowen, P., Edwards, P. and Lingard, H. (2012). Workplace stress experienced by construction professionals in South Africa. Journal of Construction Engineering and Management, 139(4): 393-403.

22. Shariat, A., Tamrin, Sh. Bahri Mohd, Arumugam, M., Danaee, M. and Ramasamy, R.. "Prevalence Rate of Musculoskeletal Discomforts Based on Severity Level Among Office Workers" Acta Medica Bulgarica, vol.43, no.1, 2016, pp.54-63.

23. Enshassi, A., El-Rayyes, Y. and Alkilani, S. (2015). Job stress, job burnout and safety performance in the Palestinian construction industry. Journal of Financial Management of Property and Construction, 20(2): 170187

24. Last . Zheng, L., Xiang, H., Song, X. and Wang, Z. (2010). Nonfatal unintentional injuries and related factors among male construction workers in central China. American Journal of Industrial Medicine, 53(6): 588-595.

25. Leung M. , Structural linear relationships between job stress, burnout, psychological stress \& performance of construction project manager. Engineering, construction management, 18(3):312-328.

26. YIP B., Rowlinson, Coping stratergies as moderators in the relationship between role overload and burnout. Construction management \& economics,26(8):871-882.

How to cite this article: Gajjar HA, T. Kanna Amarnath. Prevalence of organizational stress, burnout and work-related musculoskeletal discomfort (WMSD) among civil engineers - an observational study. Int J Health Sci Res. 2021; 11(8): 27-34. DOI: https://doi.org/10.52403 /ijhsr.20210805 